\title{
How do Financial Intermediaries Create Value in Security Issues?*
}

\author{
FABRIZIO ADRIANI ${ }^{1}$, LUCA G. DEIDDA ${ }^{2}$ and SILVIA \\ SONDEREGGER ${ }^{3}$ \\ ${ }^{1}$ Department of Economics, University of Leicester; ${ }^{2}$ Università di Sassari and CRENoS; \\ ${ }^{3}$ School of Economics, University of Nottingham, and CeDEx
}

\begin{abstract}
We study incentive provision in a model of securities issuance with an informed issuer and uninformed investors. We show that the presence of an informed intermediary may increase surplus even if we allow for collusion between the intermediary and the issuer. Collusion is neutralized by introducing a misalignment between the interests of the issuer and those of the intermediary. To achieve this, the intermediary commits to hold some of the securities. The intermediary then underprices the remaining securities and extracts any investor surplus through a "participation fee". We provide an explanation for the diffusion of book-building and quid pro quo practices in IPOs.
\end{abstract}

JEL Classification: G24, D82

\section{Introduction}

An important function of intermediaries (such as underwriters and venture capitalists) in security issues is that of providing reliable information about the value of the securities to outside investors. This paper studies the design of incentives to mitigate adverse selection problems within this context. We concentrate on two questions. First, does certification by a financial intermediary have any value when the certifier may collude with the issuer? Second, what arrangements can be made to limit the negative effects of collusion? These are important questions, since the history of intermediation in security issues is littered

\footnotetext{
*We are indebted to the editor, Thierry Foucault, and two anonymous referees for their valuable comments and suggestions. We also thank Jean-Etienne de Bettignies, Francesco Giovannoni, Paul Grout, Bruno Jullien, Giancarlo Marini, Ronald Masulis, Bill Megginson, In-Uck Park, Giancarlo Spagnolo, Lihui Tian, Robert Waldmann, and audiences at Bocconi University (ESEM 2008), Bristol-CMPO, CeFiMS, University of Rome "Tor Vergata" and University of Toulouse (EARIE 2008) for comments. Luca Deidda gratefully acknowledges the financial support of the Regione Sardegna, L.R. N.7. A previous version of this paper was circulated under the title: "Oversignaling Versus Underpricing: The Role of Intermediaries in Initial Public Offerings".
}

(C) The Author 2012. Published by Oxford University Press on behalf of the European Finance Association. All rights reserved. For Permissions, please email: journals.permissions@ oxfordjournals.org 
with financial scandals, many of which involve collusion between issuers and financial intermediaries to the detriment of investors. ${ }^{1}$

To address these issues we use a mechanism design approach. We build a framework where issuers/firms may belong to one of two types: (i) they may go public for genuine liquidity reasons; or (ii) they may choose opportunistically to go public to try and sell overvalued shares to uninformed investors. ${ }^{2}$ Distinguishing between these two different cases is useful, since while there are gains from trading the first type of firms, trading the second is always inefficient. However, in our model investors are unable to discriminate between the two, and issuers are unable to credibly communicate their type to the investors. The market is thus characterized by an adverse selection problem. Our model is fully described in Section 3. In Section 4 we characterize the highest surplus that may be achieved in the absence of intermediation. Standard arguments imply that the first best level of surplus cannot be achieved and that trade breaks down if adverse selection is sufficiently strong.

In Section 5 we ask whether the presence of an expert intermediary (who is able to assess the true value of the securities) may increase surplus even if we allow for the possibility that the intermediary may collude with the issuer. We consider the case where collusion is notoriously most difficult to avoid, namely when the informed parties have symmetric information. We characterize the highest surplus that may be achieved in this case. Our findings depend on the severity of the adverse selection problem. When adverse selection is mild, the intermediary essentially takes a passive role and its presence does not increase surplus relative to a market with no intermediary. However, when adverse selection is sufficiently strong, the presence of an expert intermediary actually makes a real difference. In equilibrium, the intermediary accepts to be involved in the issuance process only if the firm is valuable to the investor. Hence, the intermediary acts as a "filter", who reliably weeds out low quality firms. This improves over a situation with no intermediary, where trade would necessarily break down under the pressure of adverse selection.

Our mechanism relies on the principle that, for the presence of the intermediary to make a difference, we need to introduce a misalignment between the interests of the issuer and those of the intermediary. Otherwise, the intermediary-issuer coalition will simply replicate the same outcome obtained in the market with no intermediary. ${ }^{3}$ An obvious way to introduce such a misalignment is to have the intermediary sharing in the investors'

1 One of the most prominent cases during the recent financial crisis involves allegations that a top US investment bank issued CDOs without disclosing to investors that "a large hedge fund,..., with economic interests directly adverse to investors..., played a significant role in the portfolio selection process" and that the fund "effectively shorted the ... portfolio it helped select". (See SEC Litigation Release No. 21489.) There is also extensive regulation geared at preventing conflicts of interests in security issues, see e.g. rule 5121 of the US Financial Industry Regulatory Authority.

2 Beyond liquidity reasons and opportunism, the literature has proposed many possible rationales that may induce a firm to go public. Contributions include Zingales (1995), Chemmanur and Fulghieri (1999), and Faure-Grimaud and Gromb (2004). See also Pagano et al. (1998) for empirical evidence.

3 This is essentially the problem that an informed intermediary would face in Jullien and Mariotti (2006). In their model, this issue is bypassed by introducing an uninformed intermediary (note however that the focus of their paper is quite different from ours). 
profits or losses. In practice, this may be achieved by having the intermediary committing to hold some of the issued securities, rather than selling all of them.

While our analysis is mostly normative, our results suggest a new way to evaluate some widespread IPO practices like underpricing, and quid pro quo. To illustrate these points, in Section 6 we present a decentralized mechanism that achieves the second best. Under this mechanism, investors pay a fixed participation fee to the intermediary in exchange for the intermediary's promise to underprice and to allocate them shares in any issue that the intermediary chooses to underwrite. This is reminiscent of the practice of allocating shares in underpriced IPOs on the basis of the trading commissions generated by buy-side clients (quid pro quo). ${ }^{4}$ The intermediary's commitment to underprice is especially interesting. Intuitively, setting high prices for the securities makes colluding with the issuer (and thus misreporting) more attractive to the intermediary. In order to retain credibility vis-á-vis the investors, the intermediary is thus forced to take a larger position in the firm. By contrast, a commitment to underprice allows the intermediary to take a smaller position, thus maximizing the amount of shares allocated to the investors. This is efficient since it maximizes the surplus generated by trade. On the other hand, an intermediary who commits to underprice needs to find a way to extract the surplus from the investor. This is done by asking investors to pay ex-ante a "participation fee". Our model thus provides a unified narrative to rationalize both IPO underpricing and quid pro quo.

Section 6 also suggests possible ways to test our theory, and provides a discussion of our results. A natural question is why the issuer himself cannot choose to share in the profits or losses of the investor in order to signal that he is not selling overvalued shares. Intuitively, the default position of the opportunistic issuers is to retain ownership of the whole firm. As a result, they are willing to sell any fraction of the firm so long as they can sell it at a premium over its real value. Conversely, an expert intermediary with an investor-like payoff can credibly signal to the market that the shares are profitable by taking a long position in the firm.

This section also discusses some further implications. A literal interpretation of our results suggests that the type of intermediary emerging from our model combines elements of a venture capitalist and of a traditional underwriter. ${ }^{5}$ Another interpretation of our results sees the intermediary as a coalition of informed investors, as in Biais et al. (2002). However, there are other (perhaps "darker") ways in which a misalignment of the interests of the issuer and those of the intermediary can be obtained, besides having the intermediaries taking a long position in the issuer's firm. For instance, the practice of asking the investors to return IPO profits to the underwriter through ex-post trading commissions may implicitly achieve this purpose (since for the underwriter to benefit from the practice, investors have to profit). More generally, it has often been argued that intermediaries may benefit from rigging the system in favor of institutional investors. In spite of these apparent drawbacks, issuing mechanisms like book-building, which make it easier to engage in quid pro quo by giving discretion to the intermediary over the allocation of shares, have come to dominate the IPO market. ${ }^{6}$ Our results suggest that the diffusion of these practices may be a consequence of incentives designed to mitigate adverse selection

\footnotetext{
${ }^{4}$ See for instance Reuter (2006) and Nimalendran et al. (2007).

5 It is not uncommon to have the same financial institution taking on both roles, see for instance Li and Masulis (2004). In most cases, however, these functions are performed by separate institutions. As explained in Section 7, our model can accommodate both cases. 6 See for instance Kutsuna and Smith (2004) and Sherman (2005).
} 
in the presence of potential collusion between intermediaries and issuers. In other words, book-building mechanisms have become widespread precisely because they help to align the incentives of the intermediary with those of the investors. Our paper thus realigns the general perception that collusion between issuers and intermediaries is the central problem of security issuance with the recent evidence on the "dark side" of IPOs, which highlights how underwriters seek to rig the process in favor of buy-side clients. Finally, Section 7 presents some concluding remarks.

\section{Related literature}

The key premise of our analysis is the existence of uncertainty about the quality of the prospects of issuing firms. Similar to the well known framework by Myers and Majluf (1984), this is assumed to be known by the issuer but only imperfectly observed by investors. Using the Myers and Majluf (1984) framework, Eckbo and Masulis (1992) argue that issuing firms may rely on underwriter certification to reduce costs associated with adverse selection. However, they do not explicitly model the underwriter's incentives to truthfully certify. This issue is addressed by the literature on financial certifiers (see for instance Booth and Smith, 1986, Chemmanur and Fulghieri, 1994, Puri, 1999, and Sherman, 1999). This literature has mostly focused on reputation as a way to discipline certifiers. ${ }^{7}$ The focus of our paper is different in two respects. First, we analyze the optimal mechanism in the presence of collusion between issuer and intermediary. Second, our aim is to assess how far incentives alone can go, abstracting from issues of reputation. This is not to say that reputation is unimportant. However, it is just one tool that the intermediary can use to align its interests with those of the investors. As Mathis et al. (2009) point out, reputation only goes so far. It is reasonable to expect that other tools will also be employed in reality, especially if this helps to relax the conditions (e.g. non-myopia, transparency) under which reputation works. The mixed evidence on the relationship between intermediary reputation and financial scandals provides further support to the notion that reputation concerns may not fully resolve the incentive problems faced by intermediaries. ${ }^{8}$

The literature on intermediation in IPOs has traditionally focused on conflicts of interests between the issuer and the intermediary, by assuming that the intermediary has private information about potential demand (see Baron 1982, and Baron and Hölmstrom, 1980). ${ }^{9}$ Biais et al. (2002) consider a model with an uninformed issuer where the intermediary has private information about both the market value of the firm and demand by retail investors. As in our case, in order to achieve revelation, the amount of shares allocated to the intermediary depends on what the intermediary reports. However, while they assume collusion between intermediary and institutional investors, we assume collusion between intermediary and issuer and derive the practice of quid-pro-quo as a result.

\footnotetext{
$\overline{7}$ Recent contributions such as Faure-Grimaud et al. (2009), Bolton et al. (2009), Fahri et al. (2008). Skreta and Veldkamp (2009) focus on "issuer shopping" for good ratings. Competition in the market for ratings clearly aligns the incentives of the issuer with those of the certifier. However, reputation is still assumed to be the main driver of certifiers' behavior.

8 See e.g. Agrawal and Cooper (2010).

9 Empirical evidence suggests that this source of information asymmetry may not always play a key role, at least in IPOs (see Muscarella and Vetsuypens, 1989).
} 
Their rationale for underpricing is also very different from ours. ${ }^{10}$ In their model, retail investors who have the funds to buy the shares make zero expected profits when choosing to buy. In our model, when adverse selection is strong, investors expect the shares they buy to be undervalued. More generally, in our model, committing to underprice is optimal because it reduces the incentive to collude with the issuer. There is, however, an important similarity in the setup. Biais et al. (2002) essentially interpret the intermediary as a coalition of informed investors. ${ }^{11}$ This interpretation may be used in our setup as well, provided that the informed investors have a larger opportunity cost of capital than the uninformed (see next section).

Another related strand of the literature has addressed the problem of information extraction by an uninformed underwriter who faces informed investors (see Benveniste and Spindt, 1989, and subsequent papers). This story provides a clear rationale for bookbuilding and underpricing. ${ }^{12}$ Intuitively, discretion over the allocation of shares is used by the underwriter to reward investors for disclosing their information. We provide an alternative rationale for book-building, which abstracts from information extraction. Indeed, in our model underpricing occurs even if the underwriter is perfectly informed. Investors who accept to pay an ex-ante participation fee to the underwriter (for instance in the form of inflated trading commissions) are rewarded with shares in underpriced issues. This arrangement allows the underwriter to extract profits from investors, while at the same time reducing the temptation to collude with the issuer.

Finally, our model is also related to the literature on mechanism design and on collusionproof implementation. Recent work by Che and Kim (2006) argues that possible issues connected with collusion may be bypassed by a mechanism that "sells the firm to the coalition". Within the context of an auction with two bidders, for instance, this would prescribe that the principal/seller should sell the good to the lower bidder for a fixed amount (arranged ex-ante), and the lower bidder should then re-sell the good to the higher bidder at a price that corresponds to its (the higher bidder's) bid. This mechanism works by creating a wedge between the interests of the members of the coalition (the two bidders). The rationale for our result is similar. In the optimal mechanism, the intermediary is forced to act as (partial) buyer when adverse selection is strong. The scope for collusion among the issuer and the intermediary is thus mitigated by placing them at opposite sides of the market. Although this implies that the shares are not fully allocated to the agent with higher valuation (the investor), this precludes trade with the uninformed investors from taking place when it would be socially inefficient.

\footnotetext{
10 Underpricing is perhaps the most robust stylized fact in the IPO literature. Possible explanations are reviewed in Ritter and Welch (2002). Cai et al. (2007) document underpricing for corporate bonds. Several papers have tried to explain underpricing as the product of signaling (examples are Allen and Faulhaber 1989, Grinblatt and Hwang 1989, and Welch 1989). See Michaely and Shaw (1994) for potential problems with these explanations.

11 See also Gondat-Larralde and James (2008).

12 See also Leite (2006) for an alternative explanation of why informed investors tend to get better allocations.
} 


\section{The model}

We consider a setup with two periods, 1 and 2 . The market is populated by a continuum of firms. A firm can be of two types: $H$ and $L$. We denote with $a_{q}, q \in\{H, L\}$, the mass of type $q$ firms. Each firm is owned by a risk neutral entrepreneur who derives utility from consumption of the firm's cash flows. We refer to owners of type $q$ firms as entrepreneurs of type $q$. Type $q$ firms pay a cash flow $\nu^{q}$ in period 2, with $\nu^{H}>\nu^{L}$. Entrepreneurs cannot borrow, and, with some probability, are hit by a liquidity shock in period 1 . If so, it becomes costly to them to wait until period 2. In particular, for an entrepreneur who experienced a liquidity shock, the discount factor equals $\beta \in(0,1)$, while the discount factor for entrepreneurs who did not experience liquidity shocks is normalized to one. ${ }^{13}$ The probability of experiencing a liquidity shock equals $h \in(0,1)$ for type $H$ entrepreneurs while, for simplicity, we let it equal to zero for type $L$ entrepreneurs. ${ }^{14}$ Liquidity shocks are private information.

For each firm, there is a risk neutral potential investor $I$ which is endowed with cash. In period 1, the investor may hold shares in the firm or invest in a safe asset yielding a gross return $R_{I}>1$ with certainty. The investor is unable to observe the firm's type.

There is also a risk neutral intermediary $B$. Similar to Biais et al. (2002), we view the intermediary as an expert investor, who uses its expertise to assess the firm's type. The intermediary can either invest in shares or in a safe asset yielding a gross return $R_{B}>R_{I}$ in period 2 . With this assumption, we capture the idea that the intermediary has a higher opportunity cost of capital than ordinary investors. ${ }^{15}$ This may happen for various reasons. For instance, the intermediary's expertise may allow her to identify better investment opportunities than other investors. Alternatively, the intermediary may be a regulated entity, subject to stricter capital adequacy requirements.

We assume $\beta \leq 1 / R_{B}$. This ensures that an entrepreneur who suffered a liquidity shock values period 2 cash flows less than $I$ (and no more than $B$ ), so that there is scope for trading the firm's shares. Accordingly, for $q=\{H, L\}$,

$$
\nu^{q}>\frac{\nu^{q}}{R_{I}}>\frac{\nu^{q}}{R_{B}} \geq \beta \nu^{q}
$$

holds. A claim to the firm's period 2 cash flows is thus worth less to an investor than to an entrepreneur who did not experience the liquidity shock (first inequality). In turn, the same claim is worth less to the intermediary than to an investor (second inequality). Finally, the intermediary values a claim to period 2 cash flows at least as much as an entrepreneur who experienced the liquidity shock (third inequality). ${ }^{16}$ We analyze the

13 This is not important for our results. What is important is that the cost of waiting to entrepreneurs who are not hit by the liquidity shock is smaller than the investors' opportunity cost of capital.

14 This essentially allows us to eliminate one type, namely type $L$ entrepreneur who experience the liquidity shock. Including this type makes the analysis more involved without changing any result.

15 If the intermediary had the same opportunity cost of capital of ordinary investors, then there would be no scope for trade between the intermediary and the investors, at least in our model with common values. As a result, there would be no scope for intermediation. 16 Assuming that the entrepreneur discounts the future more than the intermediary is not crucial, as we discuss in a "Not for Publication" Appendix. What is crucial is that $\beta \leq 1 / R_{I}$, and that $R_{I} / R_{B}$ is not too small. 
case where $\nu^{L}<\beta \nu^{H}$. As will become clear below, this condition implies that type $L$ entrepreneurs are willing to trade whenever type $H$ entrepreneurs are, so that sorting between the two types becomes particularly challenging.

Condition (1) has several implications. First, type $H$ entrepreneurs who do not experience the liquidity shock will not sell any of their firm, since they value it more than other agents. Second, if the investors were fully informed, only shares of type $H$ firms would be traded. The first best could then be achieved without any need for intermediation. An entrepreneur experiencing a liquidity shock would make a take-it-or-leave-it offer to sell the firm at a price $p=\nu^{H} / R_{I}$ and the investor would accept. Third, if the investor is uninformed, the first best cannot be achieved. Type $L$ entrepreneurs will also be active in the market, although their motives differ from that of type $H$ entrepreneurs. While type $H$ entrepreneurs would like to sell shares of their firm in order to counteract the effect of the liquidity shock, type $L$ entrepreneurs try to sell at a price that overvalues the future cash flows of their firm.

For clarity of exposition, we refer to entrepreneurs who are active in the market (type $L$ and type $H$ who experienced the shock) as "issuers," denoted with $S$. Also, we reparametrize the model as follows. We let $V_{H} \equiv \beta \nu^{H}$ and $V_{L} \equiv \nu^{L}$ denote the valuation of the firm by a type $H$ and a type $L$ issuer, respectively. Similarly, for $q=\{H, L\}$, $U_{q} \equiv \nu^{q} / R_{I}$, and $b U_{q}$, where $b \equiv R_{I} / R_{B}$, denote the firm value to the investor, $I$, and to the intermediary, $B$, respectively. Since the intermediary's valuation is equal to a fraction $b$ of the investor's valuation, we say that the intermediary has an "investor-like" payoff from holding a stake in the firm. Under the assumptions made in the previous section, $b \in\left[V_{H} / U_{H}, 1\right)$. Given (1) and $\nu^{L}<\beta \nu^{H}$, we have $U_{H}>b U_{H} \geq V_{H}>V_{L}>U_{L}>b U_{L}$. Accordingly, in a first best scenario, only shares of type $H$ firms should be traded. ${ }^{17}$ Notice also that the intermediary has a lower valuation than the issuer for shares in type $L$ firms. Finally, we denote with $\lambda \equiv a^{H} h /\left(a^{H} h+a^{L}\right)$ the probability that a randomly selected issuer is of type $H$. Given our assumptions, trade between type $H$ issuers and investors generates a gain of $U_{H}-V_{H}$, while trade between type $L$ issuers and investors generates a loss of $U_{L}-V_{L}$. Since type $L$ issuers would not trade under full information, the ex-ante full information level of surplus is given by $\lambda\left(U_{H}-V_{H}\right)$.

\section{The market with no intermediary}

In this section we analyze the surplus generated in the absence of intermediation. A feature of our setup is that players are indifferent between being allocated the full ownership of a firm with probability $\pi$ and being allocated ownership of a fraction $\pi$ of the firm with certainty, given their valuations and preferences. For short, we take $\pi$ as the probability of being allocated the ownership of the whole firm, knowing that we can always interpret it as the stake in the firm that entitles to a share $\pi$ of the firm's cashflows.

By the revelation principle, to characterize the highest surplus that may be obtained without intermediation we may restrict attention to direct revelation mechanisms. We look for Bayesian incentive compatible (BIC) direct revelation mechanisms, where a direct mechanism is BIC if truth is a Bayesian equilibrium. Let $a \in\{H, L\}$ be an announcement

17 Adriani and Deidda (2009) analyze the effectiveness of price signaling in a similar setup, showing that it may actually exacerbate rather than alleviate the adverse selection problem. 
by the issuer, and let $\pi_{a}^{y}$ denote the probability that player $y=\{S, I\}$ obtains ownership of the firm under announcement $a$. Let $T_{a}^{I}(y)$ denote the transfer to the investor and $T_{a}^{S}(y)$ the transfer to the issuer when the ownership of the firm is allocated to player $y$. The timing is as follows.

\section{Period 1:}

$\mathbf{t}=\mathbf{0}$ : Each entrepreneur observes his type $q \in\{H, L\}$ (and whether he is hit by the liquidity shock) and chooses whether to issue equity (i.e. to become an issuer).

$\mathbf{t}=\mathbf{1}$ : Each issuer, $S$, is paired with an investor, $I$.

$\mathbf{t}=\mathbf{2}$ : To each $S-I$ pair, the mechanism designer proposes a direct revelation mechanism $\left\{\pi_{a}^{y}, T_{a}^{I}, T_{a}^{S}\right\}$, for $a \in\{H, L\}, y \in\{S, I\} . S$ and $I$ decide whether to participate or not. If at least one of the players opts out, ownership is allocated to $S$.

$\mathbf{t}=\mathbf{3}$ : If both players decide to participate, $S$ makes a private report $a \in\{H, L\}$ to the mechanism designer.

$\mathbf{t}=4$ : The ownership of the firm is allocated either to $I$ or to $S$ (with probabilities $\left.\pi_{a}^{I}, \pi_{a}^{S}\right)$. Each player observes whether he is allocated the firm's ownership and/or a (possibly zero or negative) transfer.

Period 2: Cashflows are realized.

Notice that we rule out any scope from cross-subsidy across states of nature, since the entrepreneur is assumed to be informed about his type when deciding whether to become an issuer. Any BIC direct mechanism must satisfy the following constraints.

- S's incentive compatibility constraints:

$$
\left[\mathrm{IC}_{L}^{N I}\right]: \quad E T_{L}^{S}+\pi_{L}^{S} V_{L} \geq E T_{H}^{S}+\pi_{H}^{S} V_{L}
$$

and

$$
\left[\mathrm{IC}_{H}^{N I}\right]: \quad E T_{L}^{S}+\pi_{L}^{S} V_{H} \leq E T_{H}^{S}+\pi_{H}^{S} V_{H}
$$

where $E T_{a}^{S} \equiv \pi_{a}^{S} T_{a}^{S}(S)+\left(1-\pi_{a}^{S}\right) T_{a}^{S}(I)$ for $a \in\{H, l\}$. Note that subtracting $\left(\mathrm{IC}_{L}^{N I}\right)$ from $\left(\mathrm{IC}_{H}^{N I}\right)$ we obtain

$$
\left[\mathrm{IC}_{S}-\mathrm{Nec}\right]: \pi_{H}^{S} \geq \pi_{L}^{S} .
$$

Condition $\mathrm{IC}_{S}-\mathrm{Nec}$ is thus necessary for $S$ 's incentive compatibility constraints to be satisfied.

- S's participation constraints:

$$
\left[\mathrm{PC}_{S}^{N I}\right]: \begin{aligned}
& E T_{H}^{S}+\pi_{H}^{S} V_{H} \geq V_{H} \\
& E T_{L}^{S}+\pi_{H}^{S} V_{L} \geq V_{L}
\end{aligned}
$$

- I's participation constraint:

$$
\left[\mathrm{PC}_{I}^{N I}\right]: \quad \lambda\left\{E T_{H}^{I}+\left(1-\pi_{H}^{S}\right) U_{H}\right\}+(1-\lambda)\left\{E T_{L}^{I}+\left(1-\pi_{L}^{S}\right) U_{L}\right\} \geq 0
$$

where $E T_{a}^{I} \equiv \pi_{a}^{I} T_{a}^{I}(S)+\left(1-\pi_{a}^{I}\right) T_{a}^{I}(I)$ for $a \in\{H, l\}$.

- Budget balance:

$$
\left[\mathrm{BB}^{N I}\right]: \quad T_{a}^{I}(y)+T_{a}^{S}(y) \geq 0 \forall a \in\{H, L\}, y \in\{S, I\}
$$


The optimal mechanism selects $\pi_{a}^{y}, T_{a}^{S}(y)$ and $T_{a}^{I}(y)$, for $a \in\{H, L\}$ and $y \in\{S, I\}$, to maximize the surplus

$$
W^{N I} \equiv \lambda\left\{\pi_{H}^{S} V_{H}+\left[1-\pi_{H}^{S}\right] U_{H}\right\}+(1-\lambda)\left\{\pi_{L}^{S} V_{L}+\left[1-\pi_{L}^{S}\right] U_{L}\right\}-W_{0}
$$

where $W_{0}=\lambda V_{H}+(1-\lambda) V_{L}$, subject to constraints $\mathrm{IC}_{L}^{N I}, \mathrm{IC}_{H}^{N I}, \mathrm{PC}_{S}^{N I}, \mathrm{PC}_{I}^{N I}$ and $\mathrm{BB}^{N I}$. More precisely, $W^{N I}$ measures the value generated by a mechanism over the status quo $\left(W_{0}\right)$ in which the firm is fully owned by the issuer.

Proposition 1. In the market with no intermediary, no incentive compatible mechanism achieves the first best. The surplus generated in the optimal mechanism is

$$
W^{N I *}=\left\{\begin{array}{cc}
\lambda U_{H}+(1-\lambda) U_{L}-W_{0} & \text { if } \lambda \geq \frac{V_{L}-U_{L}}{U_{H}-V_{H}+V_{L}-U_{L}} \\
0 & \text { Otherwise. }
\end{array}\right.
$$

Proof 1. $W^{N I}$ is increasing in $\pi_{L}^{S}$ and decreasing in $\pi_{H}^{S}$. Given $U_{H}>V_{H}$, allocating shares of $H$ firms to $I$ increases surplus. Symmetrically, given $U_{L}<V_{L}$, allocating shares of $L$ firms to $I$ reduces surplus. The first best thus requires that $\pi_{H}^{S}=0$ and $\pi_{L}^{S}=1$. This would however violate condition $\mathrm{IC}_{S}-\mathrm{Nec}$. As a result, the first best level of surplus cannot be achieved. An expected level of surplus equal to 0 can always be obtained by setting $\pi_{H}^{S}=\pi_{L}^{S}=1$ and $T_{a}^{S}(y)=T_{a}^{I}(y)=0$ for all $a \in\{H, L\}$ and $y \in\{S, I\}$. Given $\pi_{H}^{S} \geq \pi_{L}^{S}$, if $\lambda\left(U_{H}-V_{H}\right)+(1-\lambda)\left(U_{L}-V_{L}\right) \geq 0$, then it is optimal to set $\pi_{H}^{S}=\pi_{L}^{S}=0$, which yields $W^{N I}=\lambda U_{H}+(1-\lambda) U_{L}-W_{0}$. This can be achieved by setting $\left.\right|_{a=q} T_{a}^{S}(I)=-\left.\right|_{a=q} T_{a}^{I}(I)=V_{q}$ and $T_{a}^{S}(S)=-T_{a}^{I}(S)=0$ for all $a \in\{H, L\}$. It is straightforward to check that this mechanism satisfies all constraints by construction.

The reason why the first best cannot be achieved is standard. The first best requires that the ownership of type $L$ firms stays with the issuer while the ownership of type $H$ firms be allocated to the investor. However, any combination of transfers and quantity of shares to be allocated to $S$ that type $H$ issuers would find attractive would necessarily attract also type $L$ issuers. The tools at the disposal of the mechanism designer do not allow for meaningful screening.

The best outcome that can be achieved is associated with a mechanism where for both type $H$ and type $L$ firms, the same fraction of shares $\pi$ is allocated to the investor. A market where issuers and investors trade directly would implement such an outcome through a pooling equilibrium. However, if adverse selection is sufficiently strong, pooling violates the investor's participation constraint. In this case, the optimal mechanism would be one that generates zero surplus. In fact, whenever the adverse selection is sufficiently strong ( $\lambda$ is sufficiently low), a market where issuers and investors trade directly would break down.

\section{The Intermediary as an expert investor}

We now ask whether introducing a fully informed intermediary (an expert investor), $B$, who may collude with the issuer, makes any difference. A first effect of the presence of an informed intermediary is trivial. If $V_{H}<b U_{H}$, then $B$ has a higher valuation for type $H$ shares than $S$. As a result, the presence of the intermediary gives a type $H$ issuer the option to trade with an informed counterparty. This effect is however not particularly 
interesting. While we present our results for the general case $b \geq V_{H} / U_{H}$, the reader may want to focus on the special case $b=V_{H} / U_{H}$ where $B$ and $S$ have the same valuation for type $H$ firms, so that trading between $S$ and $B$ does not generate surplus. ${ }^{18}$

A second effect to be taken into account is that, by introducing an informed intermediary, we are de facto injecting information into the problem at no cost. If the intermediary is fully informed but is not allowed to collude with the issuer, then there are trivial mechanisms that induce revelation and achieve the first best. The most obvious mechanism consists in just asking the intermediary to reveal her information by giving her a fixed transfer that is independent of her announcement. Clearly enough, the intermediary has no incentive to lie. The mechanism thus assigns the ownership of the firm to the investor if and only if the intermediary announces $H$. Another mechanism that induces the first best consists in asking both the issuer and the intermediary to report the type of the firm and then comparing the two announcements. If both announce $H$, then the ownership of the firm is assigned to the investor with probability one. If both announce $L$, then the ownership of the firm is assigned to the issuer with probability one. If the two announcements do not coincide, then whoever announced $H$ gets the firm. It is immediate to check that there exist equilibria such that reporting the truth is incentive compatible (so that both the issuer and the intermediary will not lie). The issuer has incentive to report $L$ when the firm is of type $L$ because if he reports $H$ he will be allocated ownership of the firm anyway, given that the intermediary tells the truth. The intermediary has incentive to report $L$ when the firm is of type $L$ because if she reports $H$ she will be allocated the ownership of the firm, given that the issuer tells the truth. It is thus immediate to check that this mechanism achieves the first best.

However, these mechanisms do not work when $S$ and $B$ may collude. ${ }^{19}$ This is problematic, since in both mechanisms, $S$ and $B$ have an incentive to coordinate their reports. In the first one, $B$ could offer to a type $L$ issuer a side contract where she commits to report $H$ in exchange for a transfer. Similarly, in the second one, $B$ could offer a type $L$ issuer a side contract where both commit to report $H$ and then share the proceeds.

The main question of the paper is accordingly whether the intermediary's information may be of any value when the intermediary is allowed to collude with the issuer. The answer to this question is not obvious. By analyzing the case of a fully informed intermediary, we are considering a scenario with perfectly correlated types and symmetric information within the intermediary-issuer coalition. This is the case where collusion is notoriously most abrasive (see e.g., Laffont and Martimort, 2000).

Our analysis starts with the observation that, if the intermediary's interests are aligned with those of the issuer, then the $B-S$ coalition will simply replicate the outcome obtained in the previous section. To neutralize the potential for collusion, we therefore need to introduce a misalignment between their interests. As will become clear below, the intermediary's investor-like payoff can in fact be exploited to this purpose.

In what follows, we focus on mechanisms that are "collusion proof", in the sense that the $S-B$ coalition cannot increase its profits by altering the behavior of its members.

\footnotetext{
$\overline{18}$ It is possible to show that, provided that $b$ is not too small, the presence of an intermediary may improve upon a situation where the intermediary is absent, even when $b<V_{H} / U_{H}$.

19 Another problem affecting the first mechanism (but not the second) is that it fails as soon as the intermediary has a vanishingly small cost of acquiring information (i.e. if for instance looking at the firm's reports is costly). If the intermediary gets a fixed transfer, then the cost of information must be exactly zero.
} 


\subsection{COLLUSION-PROOF MECHANISMS}

This section characterizes the maximum welfare that may be achieved by a collusion-proof mechanism. Let $a=\left\{a_{B}, a_{S}\right\} \in\{H, L\}^{2}$ be the announcement made by $S$ and $B$. Let $\pi_{a}^{y}$ denote the probability that the player $y \in\{B, S, I\}$ is allocated the ownership of the firm under announcement $a$, with $\pi_{a}^{B}+\pi_{a}^{S}+\pi_{a}^{I}=1$. Let $T_{a}^{I}(y)$ denote the transfer to $I, T_{a}^{S}(y)$ the transfer to $S$, and $T_{a}^{B}(y)$ the transfer to $B$ when ownership allocated to $y \in\{B, S, I\}$ under announcement $a$.

Since information is perfect within the coalition, Coase theorem can be invoked to argue that the coalition can always resolve any externality through decentralized contracting. As a result, there is no loss of generality in restricting attention to mechanisms where transfers are made to the coalition (rather than to $S$ or $B$ individually) and the coalition makes a single joint report $a \in\{H, L\}$. The standard version of the revelation principle thus applies. We can accordingly restrict attention to BIC direct revelation mechanisms. The timing is as follows.

\section{Period 1:}

$\mathbf{- t}=\mathbf{0}$ : Entrepreneurs observe their type $q \in\{H, L\}$ (and whether they are hit by the liquidity shock) and choose whether to issue shares.

$-\mathbf{t}=\mathbf{1}$ : Each issuer, $S$, is paired with an investor, $I$. The intermediary, $B$, observes the firm's type.

$\mathbf{- t}=\mathbf{2}$ : The mechanism designer proposes a direct revelation mechanism $\left\{\pi_{a}^{y}, T_{a}^{I}, T_{a}^{C}\right\}$, for $a \in\{H, L\}, y \in\{B, S, I\} . S, B$, and $I$ decide whether to participate or not. If at least one of the players opts out, the shares stay with the coalition.

$\mathbf{- t}=\mathbf{3}$ : If all players decide to participate, the coalition makes a private announcement $a \in\{H, L\}$.

$-\mathbf{t}=4$ : Shares are allocated to $B, S$, or $I$ (with probabilities $\pi_{a}^{B}, \pi_{a}^{S}, \pi_{a}^{I}$ ). Each player observes whether he has been allocated ownership of the firm and/or a (possibly zero or negative) transfer.

Period 2: Cashflows are realized.

By assuming that at stage $t=2$, both $B$ and $S$ are already informed about the firm's type, we rule out any scope from cross-subsidy across states of nature. Any BIC collusionproof mechanism must satisfy the following constraints.

- Coalition's Incentive Compatibility Constraints:

$$
\begin{array}{cl}
{\left[\mathrm{IC}_{H}\right]:} & \pi_{H}^{B} b U_{H}+\pi_{H}^{S} V_{H}+E T_{H}^{C} \geq \pi_{L}^{B} b U_{H}+\pi_{L}^{S} V_{H}+E T_{L}^{C} \\
{\left[\mathrm{IC}_{L}\right]:} & \pi_{L}^{B} b U_{L}+\pi_{L}^{S} V_{L}+E T_{L}^{C} \geq \pi_{H}^{B} b U_{L}+\pi_{H}^{S} V_{L}+E T_{H}^{C}
\end{array}
$$

where $E T_{a}^{C} \equiv \pi_{a}^{B} T_{a}^{C}(B)+\pi_{a}^{S} T_{a}^{C}(S)+\left(1-\pi_{a}^{B}-\pi_{a}^{S}\right) T_{a}^{C}(I)$ for $a \in\{H, L\}$. Notice that we assume that the mechanism can allocate the firm either to $B$ or $S$. As we discuss in the next section, since the coalition may have incentive to trade ex-post, it is important that the identity of the holder of the securities should be verifiable.

- Coalition's Participation Constraints:

$$
\left[\mathrm{PC}_{H}\right]: \quad E T_{H}^{C} \geq b U_{H}
$$




$$
\left[\mathrm{PC}_{L}\right]: \quad E T_{L}^{C} \geq V_{L}
$$

In what follows the union of $\mathrm{PC}_{H}$ and $\mathrm{PC}_{L}$ is denoted as $\mathrm{PC}_{C}$ for brevity.

The participation constraints may require some explanation. If the coalition were to decide not to participate its members could still trade among themselves. The payoff that the coalition would accordingly achieve is $b U_{H}$ when the firm is of type $H$ and $V_{L}$ when the firm is of type $L$.

- Investor's Participation Constraint:

$$
\begin{aligned}
{\left[\mathrm{PC}_{I}\right]: } & \lambda\left\{E T_{H}^{I}+\left(1-\pi_{H}^{B}-\pi_{H}^{S}\right) U_{H}\right\}+ \\
& (1-\lambda)\left\{E T_{L}^{I}+\left(1-\pi_{L}^{B}-\pi_{L}^{S}\right) U_{L}\right\} \geq 0
\end{aligned}
$$

where $E T_{a}^{I} \equiv \pi_{a}^{B} T_{a}^{I}(B)+\pi_{a}^{S} T_{a}^{I}(S)+\left(1-\pi_{a}^{B}-\pi_{a}^{S}\right) T_{a}^{I}(I)$ for $a \in\{H, L\}$.

- Budget Balance:

Since no funds can be injected into the system, we require

$$
\text { [BB] : } \quad T_{a}^{I}(y)+T_{a}^{C}(y) \leq 0 \text { for all } a \in\{H, L\} \text { and } y \in\{B, S, I\}
$$

The optimal mechanism selects $\pi_{a}^{y}, T_{a}^{C}(y)$ and $T_{a}^{I}(y)$, for $a=H, L$ and $y=S, B, I$, to maximize the surplus

$$
\begin{aligned}
W \equiv & \lambda\left\{\pi_{H}^{B} b U_{H}+\pi_{H}^{S} V_{H}+\left(1-\pi_{H}^{B}-\pi_{H}^{S}\right) U_{H}\right\}+ \\
& (1-\lambda)\left\{\pi_{L}^{B} b U_{L}+\pi_{L}^{S} V_{L}+\left(1-\pi_{L}^{B}-\pi_{L}^{S}\right) U_{L}\right\}-W_{0}
\end{aligned}
$$

subject to the constraints $\mathrm{IC}_{H}, \mathrm{IC}_{L}, \mathrm{PC}_{C}, \mathrm{PC}_{I}$ and $\mathrm{BB}$. More precisely, $W$ measures the surplus associated to mechanisms that contemplate reallocating shares to the intermediary and/or an investor relative to the status quo $\left(W_{0}\right)$ where the firm is fully owned by the issuer. Comparing expression $(W)$ with the surplus $\left(W^{N I}\right)$ for the case of no intermediary, it is clear that $W$ reduces to $W^{N I}$ whenever $\pi_{H}^{B}=\pi_{L}^{B}=0$, i.e. when shares are never allocated to the intermediary. However, the possibility of allocating shares to the intermediary, who has a valuation that may be different from those of other players, may affect the surplus generated by the mechanism. If $b>V_{H} / U_{H}$, it is possible to directly generate surplus by reallocating (reported) type $H$ shares within the coalition. As already mentioned, since this is not the effect we are interested in, one may want to focus on the special case where $b=V_{H} / U_{H}$ so that the issuer and the intermediary have exactly the same valuation from type $H$ shares. In this case, reallocating type $H$ shares within the coalition has no direct effect on the surplus generated by the mechanism.

Note that $\mathrm{IC}_{H}$ and $\mathrm{IC}_{L}$ can be rewritten as

$$
\left(\pi_{H}^{B}-\pi_{L}^{B}\right) b U_{H}-\left(\pi_{L}^{S}-\pi_{H}^{S}\right) V_{H} \geq E T_{L}^{C}-E T_{H}^{C}
$$

and

$$
\left.\left(\pi_{H}^{B}-\pi_{L}^{B}\right) b U_{L}-\left(\pi_{L}^{S}-\pi_{H}^{S}\right)\right) V_{L} \leq E T_{L}^{C}-E T_{H}^{C}
$$

For these two constraints to be satisfied simultaneously, it is therefore necessary that

$$
\left[\mathrm{IC}_{C}-\mathrm{Nec}\right]:\left(\pi_{H}^{B}-\pi_{L}^{B}\right) b\left(U_{H}-U_{L}\right) \geq\left(\pi_{L}^{S}-\pi_{H}^{S}\right)\left(V_{H}-V_{L}\right) .
$$

Condition $\mathrm{IC}_{C}-\mathrm{Nec}$ is necessary for the coalition's incentive compatibility to be satisfied.

Lemma 1. No collusion-proof mechanism achieves the first best. 
Proof 2. Notice that $W$ is linearly increasing in $\pi_{L}^{S}$ and decreasing in $\pi_{H}^{B}, \pi_{H}^{S}$, and $\pi_{L}^{B}$. Hence, the first best has $\pi_{L}^{S}=1$ and $\pi_{H}^{B}=\pi_{H}^{S}=\pi_{L}^{B}=0$. It is immediately verified that this violates $\mathrm{IC}_{C}$-Nec. Hence, no collusion proof mechanism achieves the first best.

Lemma 2. Any optimal mechanism has $\pi_{L}^{B}=0$.

Proof 3. Assume, by contradiction, an optimal mechanism $M$ characterized by $\pi_{L}^{B}>0$. Let $\tilde{M}$ be a mechanism identical to $M$ except that $\tilde{\pi}_{L}^{B}=0$ and $\tilde{\pi}_{L}^{S}=\pi_{L}^{B}+\pi_{L}^{S}$. It is immediate to verify that if $M$ satisfies $\mathrm{IC}_{H}, \mathrm{IC}_{L}, \mathrm{PC}_{C}, \mathrm{PC}_{I}, \mathrm{BB}$, then $\tilde{M}$ also satisfies them. Moreover, given $b U_{L}<V_{L}$, the surplus generated by $\tilde{M}$ is greater than that generated by $M$. Hence, $M$ cannot be optimal.

Lemma 3. For any mechanism with $\pi_{H}^{S}>0$ satisfying constraints $I C_{H}, I C_{L}, P C_{C}, P C_{I}$, and $B B$, there exists an alternative mechanism with $\pi_{H}^{S}=0$ which satisfies all constraints and guarantees at least the same surplus.

Proof 4. Consider a mechanism $M$ characterized by $\pi_{H}^{S}>0$. Let $\tilde{M}$ be a mechanism identical to $M$ except that $\tilde{\pi}_{H}^{S}=0$ and $\tilde{\pi}_{H}^{B}=\pi_{H}^{B}+\pi_{H}^{S}$. If $M$ satisfies the constraints $\mathrm{IC}_{H}$, $\mathrm{IC}_{L}, \mathrm{PC}_{C}, \mathrm{PC}_{I}$, and $B B$ then also $\tilde{M}$ satisfies them. Moreover, given $b U_{H} \geq V_{H}$, the surplus generated by $\tilde{M}$ cannot be lower than that generated by $M$.

Lemmata 2-3 imply that we can restrict attention to mechanisms such that, when $a=H$ is announced, the firm's ownership can be allocated either to $B$ or to $I$, while when $a=L$ it can be allocated either to $S$ or to $I$. The surplus, $W$, can then be rewritten as

$$
W\left(\pi^{B}, \pi^{S}\right)=\lambda\left[\pi^{B} b U_{H}+\left(1-\pi^{B}\right) U_{H}\right]+(1-\lambda)\left[\pi^{S} V_{L}+\left(1-\pi^{S}\right) U_{L}\right]-W_{0}
$$

where $\pi^{B} \equiv \pi_{H}^{B}$ and $\pi^{S} \equiv \pi_{L}^{S}$. Note that, if a) $b=V_{H} / U_{H}$ (so that there are no gains from trading type $H$ shares within the coalition), and b) the coalition is treated as a single player, then the surplus function $W$ reduces to $W^{N I}$, namely the surplus function for the case of no intermediary. ${ }^{20}$ This clarifies that our results also apply to the special case where the presence of an intermediary has no direct effect on surplus.

Given Lemmata 2-3, condition $\left(\mathrm{IC}_{C}-\mathrm{Nec}\right)$ becomes

$$
\left[\mathrm{IC}_{C}-\mathrm{Nec}^{\prime}\right]: \quad \pi^{B} \geq \pi^{S} \frac{V_{H}-V_{L}}{b\left(U_{H}-U_{L}\right)} .
$$

Accordingly, if $\pi^{B}=0$ (its first best value), condition $\left(\mathrm{IC}_{C}-\mathrm{Nec}^{\prime}\right)$ implies that $\pi^{S}=0$ is also required. Similarly, if $\pi^{S}=1$ (as in the first best), then condition $\left(\mathrm{IC}_{C}-\mathrm{Nec}^{\prime}\right)$ says that $\pi^{B}=\left(V_{H}-V_{L}\right) / b\left(U_{H}-U_{L}\right)$ is required. Condition $\left(\mathrm{IC}_{C}-\mathrm{Nec}^{\prime}\right)$ thus clarifies the nature of the trade-off. On the one hand, allocating shares of type $L$ firms to the investor reduces expected surplus since $I$ has a lower valuation than $S$. On the other hand, preventing the allocation of shares of type $L$ firms to $I$ comes at a cost. That is, any mechanism such that $\pi^{S}=1$ must satisfy $\pi^{B}>0$. In other words, if $I$ is never to be allocated shares of type

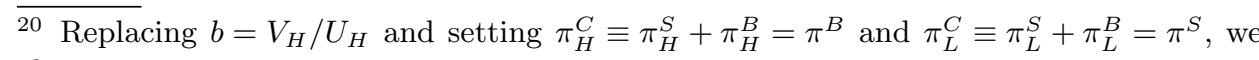
obtain

$$
W=\lambda\left\{\pi_{H}^{C} V_{H}+\left[1-\pi_{H}^{C}\right] U_{H}\right\}+(1-\lambda)\left\{\pi_{L}^{C} V_{L}+\left[1-\pi_{L}^{C}\right] U_{L}\right\}-W_{0}
$$

which is identical to $W^{N I}$. 
$L$ firms, then the intermediary - who has a lower valuation than the investor for type $H$ shares - must be allocated shares of type $H$ firms with positive probability. The coalition has thus incentive to truthfully report $L$ since, by misreporting $H$, the intermediary would have to hold type $L$ shares (which hurts the coalition's profits) with positive probability.

The next result provides an upper bound for the surplus that can be obtained through any collusion-proof mechanism.

Proposition 2. In an any collusion-proof mechanism, $W$ is bounded above by

$$
\bar{W}(\lambda)=\left\{\begin{array}{cc}
W\left(\frac{V_{H}-V_{L}}{b\left(U_{H}-U_{L}\right)}, 1\right) & \lambda<\lambda^{*} \\
W(0,0) & \lambda \geq \lambda^{*}
\end{array}\right.
$$

where

$$
\lambda^{*} \equiv \frac{\left(V_{L}-U_{L}\right) b\left(U_{H}-U_{L}\right)}{\left(V_{L}-U_{L}\right) b\left(U_{H}-U_{L}\right)+(1-b) U_{H}\left(V_{H}-V_{L}\right)} .
$$

Proof 5. Any incentive compatible mechanism must satisfy condition $\mathrm{IC}_{C^{-}}-\mathrm{Nec}^{\prime}$. Since $W\left(\pi^{B}, \pi^{S}\right)$ is strictly decreasing in $\pi^{B}$, surplus is highest when $\mathrm{IC}_{C^{-}} \mathrm{Nec}^{\prime}$ binds. Substituting for $\pi^{B}=\pi^{S} \frac{V_{H}-V_{L}}{b\left(U_{H}-U_{L}\right)}$ in $W\left(\pi^{B}, \pi^{S}\right)$, we obtain

$$
\lambda U_{H}\left(1-(1-b) \frac{V_{H}-V_{L}}{b\left(U_{H}-U_{L}\right)} \pi^{S}\right)+(1-\lambda)\left[\pi^{S} V_{L}+\left(1-\pi^{S}\right) U_{L}\right]-W_{0}
$$

The derivative of the above with respect to $\pi^{S}$ is $-\lambda U_{H}(1-b) \frac{V_{H}-V_{L}}{b\left(U_{H}-U_{L}\right)}+(1-$ $\lambda)\left(V_{L}-U_{L}\right)$, which is strictly positive if and only if $\lambda<\lambda^{*}$, and it is strictly negative otherwise.

The arguments we used to derive Proposition 2 only take into account the coalition's incentive compatibility constraint. For this reason, it is not possible to claim at this stage that $\bar{W}(\lambda)$ is the second best level of surplus. In principle, $\bar{W}(\lambda)$ might not be achievable without violating some participation constraint. In the next section, we propose a decentralized mechanism that achieves $\bar{W}(\lambda)$, which in turn proves that $\bar{W}(\lambda)$ is indeed the second best level of surplus.

Aside from this issue, Proposition 2 suggests that the allocation of shares among the different players may change according to the value of $\lambda$. If adverse selection is relatively unimportant $\left(\lambda \geq \lambda^{*}\right)$, shares are always allocated to the investor independently of the coalition's report $\left(\pi^{B}=\pi^{S}=0\right.$, so that $\left.\pi^{I}=1\right)$. Intuitively, if $\lambda$ is large, the expected cost of trading shares of type $L$ firms is low. Conversely, when adverse selection is pervasive $\left(\lambda<\lambda^{*}\right)$, the cost of allocating shares of type $L$ to investors is large, so that, whenever the coalition reports $a=L$, the shares are allocated to the issuer. When the coalition reports instead $a=H$, shares are allocated either to the intermediary or to the investor.

Finally, note that $W(0,0)=\lambda U_{H}+(1-\lambda) U_{L}-W_{0}$. Therefore, Proposition 2 shows that whenever adverse selection is unimportant $\left(\lambda \geq \lambda^{*}\right)$, including an intermediary does not change the the maximum surplus that can be achieved. ${ }^{21}$ Therefore, introducing an intermediary has no consequence on welfare. Things are different when adverse selection bites $\left(\lambda<\lambda^{*}\right)$. In this case, Proposition 2 shows that the possibility of allocating shares to an intermediary may potentially be welfare-improving.

21 It is straightforward to show that $\lambda^{*}>\frac{V_{L}-U_{L}}{U_{H}-V_{H}+V_{L}-U_{L}}$. 


\section{Implementation}

In this section we present a game - the underwriting game - which implements the optimal mechanism characterized in the previous section. A key feature of that optimal mechanism is that the intermediary directly exposes herself, by holding part of the firm's shares or alternatively by holding all of them with some probability (rather than to sell them to the investor). This shares similarities with Biais et al. (2002), who interpret the intermediary in their model as a coalition of informed investors. An interpretation more specific to our model sees the intermediary as performing two separate functions, namely holding a stake in the firm and managing the public offer. These two functions may coexist within the same institution (e.g. a universal bank) or may be performed by separate entities (e.g. a venture capitalist and an underwriter). In both cases, the intermediary commits to hold the shares until the uncertainty is resolved. Empirical evidence shows that venture capitalists usually retain a significant stake in IPO firms even after the IPO ${ }^{22}$ The model offers a possible rationale for this, namely the need to align the intermediary's incentives with those of outside investors in order to ensure the success of the IPO. We will come back to this interpretation in the next section.

Beside acquiring a stake in the company before the IPO, there are other ways in which an intermediary may commit to expose herself to the risk that the firm turns out to be a lemon. The underwriting process itself may leave the underwriter with unsold securities, or may entail informal commitments to buy shares ex-post. For instance, it is well known that underwriters are usually involved in a series of price stabilization activities in the aftermarket, which lead to the build up of large inventory positions. ${ }^{23}$ Paraphrasing Ellis et al. (2000), by underwriting the intermediary implicitly commits to intervene in the market to stabilize the price, should it fall. All commitments to ex-post price stabilization can be interpreted as exposure to the risk that shares are overpriced. However, assuming that the intermediary directly holds the shares is an easier way to capture a more general principle. We thus assume that the intermediary commits to hold the shares with probability $\pi$ (or equivalently to keep a fraction $\pi$ with certainty) and to offer the shares to $I$ with probability $1-\pi$ (or to offer $I$ a fraction $1-\pi$ ). We refer to $\pi$ as the intermediary's position in relation to the issued securities. Our simple setup assumes that the intermediary is able to credibly commit to keep her position in the firm until the true value of the securities is publicly known. This requires that it should be possible to contract on the identities of the holders of issued securities, and that such contracts should be enforceable. There is circumstantial evidence to suggest this may be feasible. An example is provided by the common practice of imposing "lock-up" provisions that ban venture capitalists (and other insiders) from selling their shares for a period after the offering. Finally, it is worth noting that in the game we present the intermediary is able to appropriate all surplus generated by trade. While this assumption is not crucial for our results, it is reasonable if the intermediary's expertise is a scarce resource. ${ }^{24}$ In the concluding remarks section we will briefly discuss what may happen when the the intermediary faces competitive pressures.

\footnotetext{
22 See e.g. Barry et al. (1990) and Megginson and Weiss (1991).

23 See for instance Aggarwal (2000). See also Chen and Wilhelm (2008) for an alternative explanation of stabilization activities.

24 There is evidence that the IPO market is not competitive. See Chen and Ritter (2000). Hansen (2001) suggests that intermediaries may compete on other dimensions than the gross spread.
} 
Before we formally introduce the underwriting game, $\mathcal{U}$, it is instructive to have an informal discussion on how the optimal mechanism may be implemented. Essentially, implementation can be seen as a two-step process. Step 1: The intermediary, $B$, commits to underprice and to take a position in any future issue she will manage. The investor, $I$, makes a side payment to $B$ in exchange for the promise to be allocated underpriced shares in future issues that $B$ will bring public. Step 2: $B$ is paired with an issuer, $S$, observes his quality and chooses whether or not to bring the firm public, in which case she takes the position agreed upon ex-ante and allocates the remaining shares to $I$. The going public process thus involves not only the commitment to market the securities taken by $B$ vis-á-vis $S$, but also the choice by $B$ to expose herself to potential losses if the quality of the firm is low. The timing of $\mathcal{U}$ is as follows.

Period 1:

- $\mathbf{t}=\mathbf{0} . B$ (publicly) commits to an ask price $p^{A} \geq 0$, a position $\pi \in[0,1]$ she will take in the event that she decides to undertake the IPO, and a fixed transfer $f \in \mathbb{R}$ that $I$ must pay $B$ if he decides to participate.

- $\mathbf{t}=\mathbf{1}$. Entrepreneurs observe their type $q \in\{H, L\}$ (and whether they are hit by the liquidity shock) and choose whether to issue equity.

- t=2. $B$ is paired with issuer $S$, observes $q \in\{L, H\}$ and chooses whether to undertake the IPO, in which case she takes the position $\pi$ agreed at $t=0$, and sets a bid price $p^{B} \geq 0$. Then, if $B$ chooses to undertake the IPO and $S$ accepts the bid price, $B$ obtains all the shares from $S$. A fraction $1-\pi$ is then reallocated to $I$ at price $p^{A}$. Otherwise, the game ends and all obtain the payoffs accrued up to this stage.

Period 2: Cashflows are realized.

At $t=0, B$ 's strategy consists in setting an ask price $p^{A} \in[0, \infty)$, a position to take in the firm $\pi \in[0,1]$, and a transfer $f \in \mathbb{R}$ to extract from $I$. At $t=2, B$ observes the issuer's type and decides whether to undertake the IPO. In that case, $B$ also offers a price $p^{B}$ to $S$. The intermediary's strategy therefore maps $[0, \infty)^{2} \times[0,1] \times\{H, L\}$ into a binary decision set (undertake, not) and into the set of possible bid prices $[0, \infty)$. $S$ 's strategy maps $S$ 's information into a binary decision set (sell, not sell). Note that $B$ never commits ex-ante to undertake the IPO. For the IPO to occur, the expected payoff to $B$ in the continuation game must exceed the payoff from choosing not to do so. This implies that the intermediary cannot use the ex-ante transfer from $I$ to offset losses arising when the decision to go ahead is taken, so that the scope for cross-subsidization between states of nature is limited.

Finally, in what follows we will discuss both the case where the ex-ante fee $f$ may take any value and the case where $f$ is restricted to be non-negative. This case may be relevant when the intermediary lacks financial resources to put up upfront.

Before stating the first result of the section, we need two definitions. Define the following tuple $\left(\pi, p^{A}, f\right)$ of $B$ 's choices at $t=0$ as the separating tuple,

$$
\begin{aligned}
\pi & =\hat{\pi} \equiv\left(V_{H}-V_{L}\right) / b\left(U_{H}-U_{L}\right) \\
p^{A} & =p^{A}(\hat{\pi}) \equiv \frac{V_{H}-\hat{\pi} b U_{H}}{1-\hat{\pi}} \\
f & =f(\hat{\pi}) \equiv \lambda\left(U_{H}-V_{H}-(1-b) \hat{\pi} U_{H}\right)=\bar{W}(\lambda)
\end{aligned}
$$

One can easily verify that $\hat{\pi}$ is the smallest position such that it is incentive compatible to undertake the IPO only when $q=H, p^{A}(\hat{\pi})<U_{H}$ is the price that yields the maximum underpricing to the investor subject to the intermediary willing to undertake the IPO, 
and $f(\hat{\pi})>0$ is equal to the upper bound on surplus given in Proposition 2. Define also the set of tuples satisfying

$$
\begin{aligned}
\pi & =0 \\
p^{A} & \geq V_{H} \\
f & =f(0) \equiv \lambda U_{H}+(1-\lambda) U_{L}-p^{A}
\end{aligned}
$$

as pooling tuples. Then,

Proposition 3. (Part A) All equilibria of $\mathcal{U}$ achieve the second best level of surplus characterized in Proposition 2. In any equilibrium, $B$ appropriates all surplus generated by trade while $S$ and $I$ both make zero profits. For all $\lambda<\lambda^{*}$ there exists a unique equilibrium where a) at $t=0 B$ chooses the separating tuple, b) at $t=2 B$ sets $p^{B}=V_{H}$ and undertakes the IPO iff $q=H$. For all $\lambda \geq \lambda^{*}$ there exist a continuum of equilibria (all yielding identical profits) such that a) at $t=0 \mathrm{~B}$ chooses a pooling tuple, b) at $t=2 \mathrm{~B}$ sets $p^{B}=V_{q}$, for $q \in\{L, H\}$, and undertakes the IPO independently of the issuer's type.

Proof. See Appendix.

Any equilibrium of $\mathcal{U}$ generates a level of (net) profits for the intermediary that are equal to the upper bound $\bar{W}(\lambda)$ characterized in Proposition 2. As a result, any equilibrium of $\mathcal{U}$ achieves the second best.

In Section 4., we observed that under extreme adverse selection a market with no intermediary is not viable. Things change if an intermediary is introduced. In this case, the intermediary operates as an effective screening device by choosing to undertake the IPO only when the firm is high quality. In other words, the intermediary allows for separation when adverse selection is extreme. Without an intermediary, any contract that attracts type $H$ issuers would attract type $L$ issuers as well. This argument does not apply to the intermediary, who has an investor-like payoff. The price that the intermediary has to pay to the issuer exceeds the intermediary's own valuation for the shares when $q=L$. This implies that the intermediary is reluctant to retain a position in type $L$ firms.

A potential problem with $\mathcal{U}$ is that it may require, when $\lambda$ takes intermediate values, that $B$ goes ahead independently of the issuer's type even if this forces expected ex-post losses on the investor. This is possible since the intermediary can always ensure that the investor ex-ante makes zero profits by subsidizing him through a negative $f$. On the other hand, the intermediary might not have enough resources to accomplish this, or it may be impossible for the investor to commit not to walk away after receiving the subsidy. We now assess the robustness of the mechanism to the additional constraint that $f$ must be non-negative. Let $\lambda^{* *} \equiv\left(V_{H}-U_{L}\right) /\left(U_{H}-U_{L}\right) \in(0,1)$.

Proposition 3. (Part B). Under the constraint $f \geq 0$, all equilibria of $\mathcal{U}$ achieve the second best if either (a) $\lambda^{* *} \leq \lambda^{*}$ or (b) $\lambda^{* *}>\lambda^{*}$ and $\lambda \notin\left(\lambda^{*}, \lambda^{* *}\right)$.

Proof. See Appendix.

In general, the constraint $f \geq 0$ is never binding in the case we are interested in, i.e. in the presence of extreme adverse selection $\left(\lambda<\lambda^{*}\right)$. From expression (28), the equilibrium value of $f$ coincides with the second-best surplus which is obviously non-negative. Problems may only arise when $\lambda \geq \lambda^{*}$. In this case, if $\lambda$ is also smaller than $\lambda^{* *}$, the additional constraint might prevent reaching the second best. 
It remains to check that, in any equilibrium of $\mathcal{U}$, the intermediary-issuer coalition cannot increase its profits by altering the behavior of its members, so that $\mathcal{U}$ is collusion proof.

Proposition 4. 1) If $f$ can take any value, then $\mathcal{U}$ is collusion-proof. 2) If $f \geq 0$ must be satisfied and either (a) $\lambda^{* *} \leq \lambda^{*}$ or $(b) \lambda^{* *}>\lambda^{*}$ and $\lambda \notin\left(\lambda^{*}, \lambda^{* *}\right)$, then $\mathcal{U}$ is collusion proof.

Proof 6 . Assume either that $f$ can take any value or that $f$ can take only positive values but either (a) or (b) hold. It is clear, from the structure of $\mathcal{U}$, that the game allows $B$ to extract all surplus from both $S$ and $I$. This implies that $B$ 's profits are given by the total surplus generated by the mechanism. Moreover, from Proposition 3 any equilibrium of $\mathcal{U}$ generates the collusion-proof second best level of surplus (i.e., the highest level of surplus that may be achieved under the restriction that the intermediary-issuer coalition should not have an incentive to alter the behavior of at least one of its members). As a result, any side contract between $B$ and $S$ would either reduce surplus or leave it unchanged. In turn, this implies that $B$ has no incentive to enter the side contract.

To sum up, Propositions 3 and 4 show that when adverse selection is sufficiently strong the presence of an informed intermediary improves welfare, and this happens in spite of the fact that the intermediary may collude with the issuer. The presence of the intermediary thus has a real effect on the functioning of the market. Note that, in equilibrium, the intermediary essentially demands that the investor pays an ex-ante "participation fee". The investor is then compensated for the ex-ante transfer through the allocation of underpriced shares. Hence, the intermediary chooses to extract profits through an ex-ante fee and commits to underprice - as opposed to simply charging a higher price to the investor.

\subsection{DISCUSSION AND IMPLICATIONS}

\subsubsection{Adverse selection and the role of intermediaries}

According to Proposition 3, $B$ chooses to always undertake the IPO independently of the quality of the firm when adverse selection is relatively unimportant (i.e. $\lambda \geq \lambda^{*}$ ). In this case, the intermediary plays a passive role and the decision to underwrite does not convey any information to the investor. In other words, the presence of the intermediary is redundant. By contrast, the role of the intermediary becomes crucial if adverse selection is sufficiently strong (i.e. $\lambda<\lambda^{*}$ ). In this case, trade would not be possible in the absence of intermediaries. The presence of an intermediary restores trade. This stems from the fact that the intermediary acts as a credible screening device, choosing to bring the issue to the public only when the firm quality is high.

\subsubsection{Relationship with Leland and Pyle (1977)}

When adverse selection is sufficiently strong, the intermediary can credibly commit not to collude with the issuer only by taking a position $\pi>0$ in the firm. In order to be able to successfully market the shares, the intermediary must thus expose herself. 
This arrangement essentially allows type $H$ to separate from type $L$. While this seems to replicate the seminal result by Leland and Pyle (1977), there are important differences. Leland and Pyle (1977) consider an environment with risk averse issuers, where the gains from trade arise from the fact that the issuers must trade in order to diversify. By contrast, in our setup the gains from trading type $H$ firms arise from the fact that the (risk neutral) issuers are hit by a liquidity shock. In our framework a type $H$ issuer is never able to separate from type $L$ by retaining partial ownership of the firm. This is because any strategy involving retaining a fraction of shares by a type $H$ issuer would be profitably mimicked by a type $L$. Hence, we are considering a payoff structure for issuers and investors where Leland's and Pyle's type of separation cannot be achieved. In this environment, the presence of an intermediary with a low valuation (relative to the issuer) for type $L$ shares can thus make up for the inability of the informed party to achieve separation.

From a more general perspective, our claim is not that there is no way in which sorting can be achieved without intermediaries. However, if sorting can be achieved by alternative means, whether there is a role for intermediaries or not depends on which screening device is cheaper. Moreover, it is likely that in practice different screening devices are used as complements. Hence, allowing for sorting without intermediaries would make the analysis more complicated but should not affect the key message of our paper.

\subsubsection{Underpricing}

According to Proposition 3, when adverse selection is pervasive, $B$ sets an ask price $p^{A}<$ $U_{H}$. However, since the intermediary undertakes the IPO only when $q=H$, the investor would be ready to pay up to $U_{H}$ for the shares. Hence, shares are underpriced.

Rather than trying to extract surplus from the investor by setting a large offer price, the intermediary prefers to underprice and extracts the expected surplus from the investor through an ex-ante transfer. The reason for this result stems from the desire to minimize the cost of collusion. As it turns out, if the intermediary is able to extract rents from the investor by other means (e.g. inflated trading commissions), using the offer price is never optimal. A high offer price increases the temptation to collude with the issuer and to undertake the IPO even when quality is low. This implies that, in order to be credible, the intermediary has to take a larger position. In turn, this reduces the amount of shares that are actually sold to the investor and thus the total surplus generated by trade. As a result, if the intermediary is able to extract the surplus through an ex-ante transfer, she would be better off by underpricing and taking a smaller position. Our model thus provides a novel rationale for underpricing: Underpricing is a way to efficiently reduce the costs of collusion and to boost trade and the total surplus generated by trade.

Things change when adverse selection is weak, so that the intermediary does not engage in screening. In this case, the intermediary takes a zero stake in the firm and the offer price does not affect the total surplus generated by trade. Intuitively, I's surplus can be equivalently extracted by the intermediary through the offer price at $t=2$ or through the ex-ante fee. As a result, the offer price - and thus underpricing - is undetermined when $\lambda \geq \lambda^{*}$.

\subsubsection{Comparative statics on $b$}

The analysis treats both the intermediary's position and the share price as endogenously determined by the primitives of the model. Our results suggest that, when $\lambda<\lambda^{*}$, 


$$
\frac{d \hat{\pi}}{d b}=-\left(V_{H}-V_{L}\right) \frac{V_{L} U_{H}-V_{H} U_{L}}{\left[b\left(U_{H}-U_{L}\right)-\left(V_{H}-V_{L}\right)\right]^{2}}<0
$$

and

$$
\frac{d p^{A}(\hat{\pi})}{d b}=-\frac{\left(V_{H}-V_{L}\right)}{b^{2}\left(U_{H}-U_{L}\right)}<0 .
$$

The equilibrium values of $\pi$ and $p^{A}$ are decreasing functions of $b$, namely the intermediary's (unobserved) opportunity cost of capital. As the value of $b$ increases, the intermediary's equilibrium position gets smaller, and the share price paid by the investor decreases - i.e., there is more underpricing.

Taking $b$ as the relevant comparative statics variable, our model thus predicts that larger positions should go hand in hand with less underpricing, and vice-versa.

To understand the negative relationship between the intermediary's position and share price, consider the incentive compatibility constraint that must be satisfied to prevent the intermediary from going ahead with low quality issues. Letting $\pi^{S}=1$ and $\pi^{B}=\pi$ in $\left(\mathrm{IC}_{C}-\mathrm{Nec}^{\prime}\right)$, this is equal to

$$
b\left(U_{H}-U_{L}\right) \pi \geq V_{H}-V_{L} .
$$

A higher opportunity cost of capital (i.e., a lower $b$ ) makes condition (34) harder to satisfy. ${ }^{25}$ This implies that, keeping everything else equal, the intermediary should hold a larger position in order to guarantee her credibility in the event she decides to undertake the IPO - i.e., $\pi$ should increase. However, since the opportunity cost of capital is high, this has the side effect of lowering the appeal to her of undertaking any IPO (even high quality) at $t=2$. To ensure that the intermediary still wants to go ahead for high quality issues, a correspondingly high share price must then be charged to the investor.

\subsubsection{Venture capital backing}

A possible interpretation of our setup sees the intermediary as a hybrid between a venture capitalist and a traditional underwriter. These two functions may coexist within the same institution or may be taken up by separate entities. Indeed, $\mathcal{U}$ assumes for simplicity that the same intermediary moves both at $t=0$ and $t=2$. However, Proposition 3 would still broadly apply if we were to assume that the agent offering the contract at $t=0$ and the one choosing whether to take a position at $t=2$ were distinct players. The $t=0$ intermediary can be interpreted as a (possibly uninformed) monopolistic underwriter. The $t=2$ intermediary is essentially an informed venture capitalist. The role of the underwriter consists in offering a contract to both the venture capitalist and the investor specifying the ex-ante fee $I$ has to pay to participate, the offer price, and the stake that the venture capitalist has to hold if the IPO is to be undertaken (alternatively, the underwriter can commit to underwrite only IPOs where the venture capitalist holds that particular stake). ${ }^{26}$ The role

$\overline{25}$ Intuitively, this is because any gain that the intermediary may make from holding a high quality rather than a low quality share is dwarfed by the high opportunity cost she incurs from having her capital tied up in the company's shares.

26 The fact that the uninformed underwriter - rather than the informed venture capitalist - has monopoly power is unimportant. The underwriter could always reallocate profits exante to the venture capital in an incentive-neutral way. 
of the venture capitalist consists in choosing whether to hold a stake $\pi$ after observing the issuer's type. When adverse selection is pervasive, the underwriter conditions her decision to undertake the IPO on the venture capitalist's willingness to retain a sizable position in the firm until the uncertainty is resolved. When adverse selection is weak, the presence of the venture capitalist plays no role.

From a modelling viewpoint, notice that, under $\mathcal{U}, B$ 's problem at $t=0$ is to give herself incentives not to "cheat" at $t=2$, after gathering information about the issuer. By setting ex-ante the size of the position that she will have to take if an IPO is to take place, $B$ essentially offers a contract to her (informed) self. It is clear that a solution to this problem is also a solution to the problem of providing another player (with the same payoff) with incentives not to cheat. This intuitively explains why the two models are equivalent.

Under this interpretation, our comparative statics results predict a negative relationship between venture capitalist shareholding and underpricing. This is broadly backed by empirical evidence. In their influential article, Barry et al. (1990) find a significant negative correlation between venture capitalist shareholding and underpricing. Li and Masulis (2007) also find that the size of the holding by financial institutions in an IPO firm is negatively correlated to underpricing.

\subsubsection{Book-building and quid pro quo}

In equilibrium, the investor makes a side-payment to the intermediary in exchange for the promise to be allocated underprices shares. This quid pro quo is reminiscent of the widespread preferential treatment (for instance in the form of preference in the allocation of shares) offered to regular purchasers of the services provided by the intermediary. Loughran and Ritter (2004) cite the example of Robertson Stephens Investment, who allocated IPOs to institutional clients "almost exclusively on the basis of the amount of commission business generated during the prior 18 months." The same authors note that "Credit Suisse First Boston (CSFB) received commission business equal to as much as $65 \%$ of the profits that some investors received." 27 The general concern for academics and regulators is that these practices, by promoting collusion between the intermediary and the investors, may be harmful to the IPO market. ${ }^{28}$ In contrast with this view, our model suggests that these practices may be the lesser of two evils. The possibility of collusion between the intermediary and the investor can be beneficial so long as it reduces the risk of the intermediary colluding with the issuer. From a theoretical viewpoint, the real danger for the viability of the market is that the two informed parties may choose to collude against the uninformed. Side payments to the intermediary by the investor allow the intermediary to appropriate some of the investors' surplus by other means than the offer price. Committing to underprice in turn reduces the temptation for the intermediary to collude with the issuer. Favoritism in the allocation of shares ensures that the investors who make side transfers can cover the cost of the transfers with the gains they reap from purchasing underpriced shares. Under this view, the widespread quid pro quo between intermediaries and investors can be seen as a custom that the market has evolved in order to sidestep the adverse selection problem and to prevent collusion between the

$\overline{27}$ See also Nimalendran et al. (2007) for indirect evidence of quid pro quo.

28 For instance, Ritter and Welch (2002) remark that "If underwriters are given discretion in share allocations, the discretion will not automatically be used in the best interests of the issuing firms." 
informed parties. Needless to say, these customs are less than ideal since they prevent fair competition and discourage entry. Our model suggests however that this may be the price that needs to be paid for the market to be viable. This reading of our results sheds a new light on the adoption of book building in IPOs. With book building, the investment bank typically has discretion over the allocation of shares to the investors. The "dark side" of book building - as most of the literature puts it - is that it promotes favoritism and quid pro quo in the allocation of shares. An implication of our result is that any policy intervention aimed at preventing favoritism and quid pro quo without also restricting the scope for collusion between the informed parties may prove counterproductive.

\section{Concluding remarks}

We have built a model where the presence of an expert intermediary increases surplus even if we allow for the possibility of collusion between the intermediary and the issuer. Our framework contains four key ingredients:

1. Issuers' outside options are increasing in their quality;

2. It is inefficient to trade low quality firms;

3. It is possible to contract on the identities of the holders of issued securities;

4. The intermediary has "investor-like" payoffs (in particular, her valuation for type $L$ issues is lower than that of the issuer).

Conditions 1 . and 2. imply that it is not possible to sort high quality issuers without attracting low quality ones as well. At the same time, though, a pooling equilibrium is inefficient. We believe that the no-sorting result could in principle be relaxed, although this would come at the cost of further analytical complication.

Conditions 3. and 4. ensure that it is possible to give incentives for revelation to the intermediary, by allocating her a fraction of the shares. Crucially, this happens in spite of the threat imposed by potential collusion with the issuer. To our knowledge, this is the first paper to address this issue. We derive the optimal contract and study its possible implementation. Intriguingly, our results match a number of unexplained features of security issues.

Although our normative approach helps to explain why some IPO practices may persist, it does not fully explain how they can be sustained. For instance, while we show that it is optimal for the intermediary to commit to underprice, our analysis is silent regarding the issue of what commitment devices the intermediary may use to achieve this. Further research should be aimed at addressing these issues. An obvious way in which the intermediary may commit is by building a reputation for underpricing. The natural question is then why the intermediary cannot build directly a reputation for honest certification. In practice, a reputation for underpricing is probably easier to establish than a reputation for truthfully disclosing information. Failure to disclose information is difficult to verify since it is often impossible to ascertain what the certifier actually knew at the time of the disclosure. On the other hand, an intermediary who fails to underprice is immediately observable and punishable by the investors. We believe that this is an interesting line of research. By reconciling our approach with the reputation-based literature on certifiers, it would provide a unified framework to understand the complementary roles of reputation and direct incentives. 
Finally, our setup is silent about the possible implications of competition. Depending on market conditions, competition among intermediaries may be directed either to attracting buy-side clients or issuers. The first form of competition would have purely redistributional effects in our setup. Similar to the case of a monopolist intermediary, the intermediary would seek to maximize expected surplus. The only difference with the underwriting game we have discussed would consist in the fact that competition among intermediaries would eliminate the ex-ante transfer, thus reallocating profits from the intermediary to the investor.

Things become more complex when competition is directed to attracting issuers. In that case, the effect of competition may no longer be confined to the ex-ante transfer. Intuitively, a contract that implements the second best and allocates all profits to the issuer by means of a transfer made before observing the issuer's type would be vulnerable to "undercutting". Other intermediaries could in principle offer contracts that pay higher prices to high quality (but not low quality) issuers. However, in order to retain their credibility, these intermediaries would be forced to take larger positions in the firm, thus generating distortions away from the second best.

\section{Appendix}

\section{PROOF OF PROPOSITION 3}

The proof starts with a full characterization of all equilibria of $\mathcal{U}$. We then show that any equilibrium implements the second best level of surplus. Finally, we turn our attention to the case with the additional constraint $f \geq 0$.

\section{Characterization of the Equilibria of $\mathcal{U}$}

We first describe $B$ 's decision to undertake the IPO at $t=2$. We then characterize the equilibria of the overall game.

$B$ 's problem at $t=2$.

At $t=2$, the position $\pi$ taken by the intermediary and the ask price $p^{A}$ are given. If the intermediary decides to go ahead, she must also set a bid price $p^{B} \geq 0$. It is straightforward to check that, when choosing to buy from $S$, for a given quality $q$ of the issue it is optimal for $B$ to always set $p^{B}=V_{q}$, i.e. the minimum price that guarantees $S$ 's participation. Expected profits at $t=2$ for an intermediary willing to go ahead when matched with a type $q$ issuer are

$$
\pi b U_{q}+(1-\pi) p^{A}-V_{q}
$$

Define

$$
\hat{p}_{q}(\pi) \equiv\left\{\begin{array}{cc}
\frac{V_{q}-\pi b U_{q}}{(1-\pi)} & \pi<1 \\
+\infty & \pi=1 \wedge q=L \\
-\infty & \pi=1 \wedge q=H
\end{array}\right.
$$


the lowest value (if one exists) of $p^{A}$ such that an intermediary matched with a type $q$ issuer makes no losses from undertaking the IPO at $t=2$. It is easy to check that

$$
\hat{p}_{H}(\pi) \leq \hat{p}_{L}(\pi) \Leftrightarrow \pi \geq \frac{V_{H}-V_{L}}{b\left(U_{H}-U_{L}\right)} \equiv \hat{\pi}
$$

Consider then $B$ 's optimal strategy. [We ignore the possibility that $B$ might want to mix at $t=2$. It is immediate to show that, if $\left(\pi, p^{A}\right)$ were such to induce mixing at $t=2$, then $B$ could do strictly better by choosing a different pair $\left(\tilde{\pi}, \tilde{p}^{A}\right)$ at $t=0$. As a result, mixing never emerges in equilibrium].

- If $p^{A} \geq \max \left\{\hat{p}_{L}(\pi), \hat{p}_{H}(\pi)\right\}$, then it is optimal for $B$ to undertake the IPO for all $q \in\{L, H\}$ (pooling). This strategy is strictly optimal if the strict inequality holds.

- If $\min \left\{\hat{p}_{L}(\pi), \hat{p}_{H}(\pi)\right\} \leq p^{A} \leq \max \left\{\hat{p}_{L}(\pi), \hat{p}_{H}(\pi)\right\}$, then it is optimal for $B$ to undertake the IPO only when $q=H$ if $\pi \geq \hat{\pi}$ and only when $q=L$ if $\pi \leq \hat{\pi}$ (separating). [Again the strategy is strictly optimal if $\min \left\{\hat{p}_{L}(\pi), \hat{p}_{H}(\pi)\right\}<p^{A}<$ $\left.\max \left\{\hat{p}_{L}(\pi), \hat{p}_{H}(\pi)\right\}\right]$.

- If $p^{A} \leq \min \left\{\hat{p}_{L}(\pi), \hat{p}_{H}(\pi)\right\}$, then it is optimal for $B$ not to undertake the IPO, strictly optimal if the strict inequality holds.

\section{Profits}

Denote with $\Pi^{B}$ and $\Pi^{I}$ the expectation at $t=0$ of net profits at $t=2$ for $B$ and $I$ respectively (clearly, $S$ makes zero profits). If $B$ chooses to undertake the IPO only for type $q \in\{L, H\}$, we have

$$
\Pi_{S E P}^{B}\left(\pi, p^{A}\right)=\mathcal{I}(q)\left[\pi b U_{q}+(1-\pi) p^{A}-V_{q}\right]
$$

and

$$
\Pi_{S E P}^{I}\left(\pi, p^{A}\right)=\mathcal{I}(q)(1-\pi)\left(U_{q}-p^{A}\right) .
$$

where $\mathcal{I}(q)=\lambda$ if $q=H$ and $\mathcal{I}(q)=1-\lambda$ if $q=L$. Expected net profits under pooling are

$$
\begin{gathered}
\Pi_{P O O L}^{B}\left(\pi, p^{A}\right)=\lambda\left[\pi b U_{H}+(1-\pi) p^{A}-V_{H}\right]+(1-\lambda)\left[\pi b U_{L}+(1-\pi) p^{A}-V_{L}\right] \\
\Pi_{P O O L}^{I}\left(\pi, p^{A}\right)=(1-\pi)\left[\lambda\left(U_{H}-p^{A}\right)+(1-\lambda)\left(U_{L}-p^{A}\right)\right] .
\end{gathered}
$$

for $B$ and $I$ respectively. Clearly enough, expected profits if $B$ chooses to never undertake the IPO are zero. We are now ready to give a full characterization of the equilibria of $\mathcal{U}$.

\section{Equilibria of the overall game}

At $t=0, B$ chooses $p^{A}, \pi$, and $f$ to maximize profits given her $t=2$ strategy and under the investor's ex-ante participation constraint $f \leq \Pi^{I}$. Clearly enough, it is always optimal for $B$ to extract ex-ante all the investor's expected profits in $t=2$ by setting $f=\Pi^{I}$ at $t=0$. As a result, $B$ 's problem reduces to choosing the pair $\left(\pi, p^{A}\right)$ that maximizes the sum $\Pi\left(\pi, p^{A}\right) \equiv \Pi^{B}\left(\pi, p^{A}\right)+\Pi^{I}\left(\pi, p^{A}\right)$. Consider then the pair $\left(\pi_{\varepsilon}, p_{\varepsilon}^{A}\right)$ consisting in $\pi_{\varepsilon}=$ $\hat{\pi}+\varepsilon$, with $\varepsilon>0$, and $p_{\varepsilon}^{A} \in\left(\hat{p}_{H}\left(\pi_{\varepsilon}\right), \hat{p}_{L}\left(\pi_{\varepsilon}\right)\right)$. As already shown, for all $\varepsilon>0$, separation at $t=2$ is the only equilibrium strategy. Denote with

$$
\hat{\Pi}_{\varepsilon} \equiv \Pi_{S E P}^{B} \cdot\left(\pi_{\varepsilon}, p_{\varepsilon}^{A}\right)+\Pi_{S E P}^{I}\left(\pi_{\varepsilon}, p_{\varepsilon}^{A}\right)=\lambda\left[U_{H}-V_{H}-(1-b) \pi_{\varepsilon} U_{H}\right]
$$

the profits from $\left(\pi_{\varepsilon}, p_{\varepsilon}^{A}\right)$ and let

$$
\hat{\Pi} \equiv \lambda\left[U_{H}-V_{H}-(1-b) \hat{\pi} U_{H}\right]
$$


denote the limit of the profits for $\varepsilon \rightarrow 0$. Since separation is the only $t=2$ outcome for $\varepsilon>0, B$ can always implement any $\hat{\Pi}_{\varepsilon}$ by choosing the pair $\left(\pi_{\varepsilon}, p_{\varepsilon}^{A}\right)$. It then follows that if a pair $\left(\pi, p^{A}\right)$ yields profits $\Pi\left(\pi, p^{A}\right)<\hat{\Pi}$, then choosing $\left(\pi, p^{A}\right)$ is not an equilibrium strategy - since there exists $\varepsilon>0$ such that $\hat{\Pi}_{\varepsilon}>\Pi\left(\pi, p^{A}\right)$. This has several implications

1. Consider an outcome where $B$ only undertakes the IPO when $q=H$. Take any pair $\left(\pi, p^{A}\right)$ such that $\pi>\hat{\pi}$. Given $\pi>\hat{\pi}$, we have

$$
\Pi\left(\pi, p^{A}\right)=\lambda\left[U_{H}-V_{H}-(1-b) \pi U_{H}\right]<\hat{\Pi} .
$$

As a result, any separating outcome where $B$ only undertakes the IPO when $q=H$ and $\pi>\hat{\pi}$ can be ruled out.

2. Consider now an outcome where $B$ never undertakes the IPO. Simple algebra shows that

$$
\hat{\Pi} \geq \lambda(1-\hat{\pi})\left(U_{H}-V_{H}\right)>0
$$

where the first inequality comes from $b \geq V_{H} / U_{H}$ and the second from $U_{H}>V_{H}$. Hence, the intermediary can always ensure herself strictly positive expected profits by choosing a pair $\left(\pi, p^{A}\right)$ such that undertaking the IPO only when $q=H$ is optimal. As a result, any pair $\left(\pi, p^{A}\right)$ that leads to never undertaking the IPO can be ruled out.

3. Finally, consider a separating outcome where $B$ only undertakes the IPO when $q=L$. From (A4) and (A5) this yields expected profits

$$
\Pi_{S E P}^{B}+\Pi_{S E P}^{I}=(1-\lambda)\left[\pi b U_{L}+(1-\pi) U_{L}-V_{L}\right]<0 .
$$

As a result, any pair $\left(\pi, p^{A}\right)$ that induce $B$ to go ahead only when $q=L$ can be ruled out.

In summary, the equilibrium can only take two forms: 1$)$ separating where $B$ chooses to undertake the IPO only when $q=H, 2)$ pooling where $B$ always undertakes the IPO. In the first case, point 1 above implies that $B$ must choose $\pi=\hat{\pi}$ and a price $p^{A}(\hat{\pi})$. Since $p_{H}(\hat{\pi})=p_{L}(\hat{\pi})$ from $(\mathrm{A} 3)$, it follows that $p^{A}(\hat{\pi})=p_{H}(\hat{\pi})=p_{L}(\hat{\pi})$, so that the separating price is uniquely determined and implies underpricing

$$
p^{A}(\hat{\pi})=\frac{V_{H}-\hat{\pi} b U_{H}}{1-\hat{\pi}}=\frac{b\left(V_{L} U_{H}-V_{H} U_{L}\right)}{b\left(U_{H}-U_{L}\right)-\left(V_{H}-V_{L}\right)}<U_{H} .
$$

where the inequality is derived by using $b \geq V_{H} / U_{H} \Rightarrow\left(V_{H}-\hat{\pi} b U_{H}\right) /(1-\hat{\pi}) \leq V_{H}<U_{H}$.

Consider now a pooling outcome. $B$ 's expected profits are

$$
\begin{aligned}
\Pi\left(\pi, p^{A}\right)= & \Pi_{P O O L}^{B}\left(\pi, p^{A}\right)+\Pi_{P O O L}^{I}\left(\pi, p^{A}\right) \\
= & \lambda\left[\pi b U_{H}+(1-\pi) p^{A}-V_{H}\right]+(1-\lambda)\left[\pi b U_{L}+(1-\pi) p^{A}-V_{L}\right]+ \\
& \lambda(1-\pi)\left(U_{H}-p^{A}\right)+(1-\lambda)(1-\pi)\left(U_{L}-p^{A}\right) \\
= & \lambda\left(U_{H}-V_{H}\right)+(1-\lambda)\left(U_{L}-V_{L}\right)-\pi(1-b)\left[\lambda U_{H}+(1-\lambda) U_{L}\right]
\end{aligned}
$$

Notice that it is always optimal for $B$ to set $\pi$ equal to zero. Notice also that profits do not depend on $p^{A}$. Given $\pi=0$, any $p^{A} \geq \hat{p}_{H}(0)=V_{H}$ generates the same amount of profits, which we denote with $\tilde{\Pi} \equiv \lambda\left(U_{H}-V_{H}\right)+(1-\lambda)\left(U_{L}-V_{L}\right)$. It is immediate to check that $\widetilde{\Pi} \geq \hat{\Pi} \Leftrightarrow \lambda \geq \lambda^{*}$. Hence, any equilibrium of $\mathcal{U}$ prescribes that

1. if $\lambda<\lambda^{*}, B$ chooses the pair $\left(\hat{\pi}, p^{A}(\hat{\pi})\right)$ at $t=0$ and goes ahead at $t=2$ only when $q=H$. 
2. if $\lambda \geq \lambda^{*}, B$ chooses any pair $\left(\pi, p^{A}\right)$ such that $\pi=0$ and $p^{A} \geq V_{H}$ at $t=0$ and always goes ahead at $t=2$.

Notice that, for exposition purposes, we used the convention that, if $\lambda=\lambda^{*}$ so that $B$ is indifferent between strategy 1 and 2 , she chooses the pooling strategy. This, however, has no bearing on our results. To complete the characterization of the equilibrium outcome, notice that both $S$ and $I$ make zero profits and that the ex-ante fee $f$ is equal to $I$ 's expected time 2 profits. Then, if $\lambda<\lambda^{*}$

$$
f(\hat{\pi})=\lambda(1-\hat{\pi})\left[U_{H}-p^{A}(\hat{\pi})\right]=\hat{\Pi} .
$$

If $\lambda \geq \lambda^{*}$, we have instead

$$
f(0)=\lambda U_{H}+(1-\lambda) U_{L}-p^{A} .
$$

To sum up, therefore, the following applies: a) when $\lambda<\lambda^{*}, B$ chooses the separating tuple, b) when $\lambda \geq \lambda^{*}, B$ chooses a pooling tuple. Having provided a full characterization of the equilibria, we now show that all equilibria of $\mathcal{U}$ obtain the second best.

\section{Second best}

From Proposition (2), the surplus generated by a second best mechanism cannot exceed $\bar{W}(\lambda)=\lambda\left(U_{H}-V_{H}\right)+(1-\lambda)\left(U_{L}-V_{L}\right) \quad$ if $\quad \lambda \geq \lambda^{*} \quad$ and $\bar{W}(\lambda)=\lambda\left[U_{H}-V_{H}-\frac{1-b}{b} \frac{V_{H}-V_{L}}{U_{H}-U_{L}} U_{H}\right] \quad$ if $\lambda<\lambda^{*}$. It is immediate to check that $\bar{W}(\lambda)=\max \{\hat{\Pi}, \widetilde{\Pi}\}$, with $\widetilde{\Pi} \geq \hat{\Pi} \Leftrightarrow \lambda \geq \lambda^{*}$. Denote with $\Pi^{e} B^{\prime}$ 's expected profits in an equilibrium $e \in \mathcal{E}$ of $\mathcal{U}$, where $\mathcal{E}$ is the set of equilibria of $\mathcal{U}$. The following statements then apply.

1. $\Pi^{e}=\max \{\hat{\Pi}, \widetilde{\Pi}\}=\bar{W}(\lambda)$ for all $e \in \mathcal{E}$.

2. Any $e \in \mathcal{E}$ achieves the second best.

Since $B$ can achieve both $\hat{\Pi}$ and $\widetilde{\Pi}$, it must be that $\Pi^{e} \geq \max \{\hat{\Pi}, \widetilde{\Pi}\}$. Otherwise $B$ would not be maximizing her profit, so that $e$ cannot be an equilibrium. However, from Proposition 2, $\Pi^{e} \leq \bar{W}(\lambda)$, i.e. $B$ cannot appropriate more than the upper bound on surplus. Otherwise, either $I$ or $S$ would make losses in expectation. But, since $\max \{\hat{\Pi}, \widetilde{\Pi}\}=$ $\bar{W}(\lambda)$, this implies that $\Pi^{e}=\max \{\hat{\Pi}, \widetilde{\Pi}\}$. The second statement trivially follows from the first and from the fact that, since $\Pi^{e}=\bar{W}(\lambda), S$ and $I$ must be making zero profits (otherwise the surplus generated would be greater than its upper bound $\bar{W}(\lambda)$ ).

\section{Proof of Part B (Additional Constraint $f \geq 0$ ).}

Here we characterize the set of values of $\lambda$ such that the constraint $f \geq 0$ does not bind, so that all our previous results apply. If $\lambda \leq \lambda^{*}$ (A15) implies $f=\hat{\Pi}>0$. Hence, the constraint is not binding. Things change if $\lambda>\lambda^{*}$. In this case, the lowest price $B$ can charge is $p^{A}=V_{H}$. Expression (A16) thus implies that $f \geq 0$ is non-binding if and only if

$$
\lambda U_{H}+(1-\lambda) U_{L} \geq V_{H} \Leftrightarrow \lambda \geq \lambda^{* *}
$$

It then follows that if $\lambda^{*} \geq \lambda^{* *}$, then the constraint $f \geq 0$ never binds. For $\lambda^{*}<\lambda^{* *}$, the constraint is binding only for $\lambda \in\left(\lambda^{*}, \lambda^{* *}\right)$. 


\section{References}

Adriani, F. and Deidda, L. G. (2009) Price Signaling and the Strategic Benefits of Price Rigidities, Games and Economic Behavior 67, 335-350.

Aggarwal, R. (2000) Stabilization Activities by Underwriters after Initial Public Offerings, Journal of Finance 55, 1075-1103.

Agrawal, A. and Cooper, T. (2010) Accounting Scandals in IPO Firms: Do Underwriters and VCs Help? Journal of Economics and Management Strategy 19, 1117-1181.

Allen, F. and Faulhaber, G. (1989) Signaling by Underpricing in the IPO Market, Journal of Financial Economics 23, 303-323.

Baron, D.P. and Hölmstrom, B. (1980) The Investment Banking Contract for New Issues Under Asymmetric Information: Delegation and the Incentive Problem, Journal of Finance 35, 1115-1138.

Baron, D.P. (1982) A Model of the Demand for Investment Banking Advising and Distribution Services for New Issues, Journal of Finance 37, 955-976.

Barry, C.B., Muscarella, C.J., Peavy, J.W., and Vetsuypens M.R. (1990) The role of venture capital in the creation of public companies: Evidence from the going-public process, Journal of Financial Economics 27, 1115-1138.

Benveniste, L.M. and Spindt, P.A. (1989) How Investment Bankers Determine the Offer Price and Allocation of New Issues, Journal of Financial Economics 24, 343-361.

Biais, B., Bossaerts, P., and Rochet, J.-C. (2002) An Optimal IPO Mechanism, Review of Economic Studies 69, 117-146.

Bolton, P., Freixas, X., and Shapiro, J. (2009) The Credit Ratings Game, NBER Working Paper No. 14712.

Booth, J.R., and Smith, R.L. II (1986) Capital raising, underwriting and the certification hypothesis, Journal of Financial Economics 15, 261-281.

Cai, N., Helwege, J. and Warga, A. (2007) Underpricing in the Corporate Bond Market Review of Financial Studies 20, 2021-2046.

Che, Y.-C. and Kim, J. (2006) Robustly Collusion-Proof Implementation, Econometrica 74, 1063-1107.

Chemmanur, T.J., and Fulghieri, P. (1994) Investment Bank Reputation, Information Production, and Financial Intermediation, Journal of Finance 49, 57-79.

Chemmanur,T.J. and Fulghieri, P. (1999) A theory of the going-public decision, Review of Financial Studies 12, 249-279.

Chen, H-C., and Ritter, J.R. (2000) The Seven Percent Solution, Journal of Finance 55, 1105-1131.

Chen, Z., and Wilhelm, W. (2008) A Theory of the Transition to Secondary Market Trading of IPOs, Journal of Financial Economics, forthcoming.

Eckbo, B.E., and Masulis, R.W. (1992) Adverse Selection and the Rights Offer Paradox, Journal of Financial Economics 32, 293-332.

Ellis, K., Michaely, R., and O'Hara, M. (2000) When the Underwriter Is the Market Maker: An Examination of Trading in the IPO Aftermarket, Journal of Finance 55, 1039-1074.

Farhi, E., Lerner, J. and Tirole, J. (2008) Fear of Rejection? Tiered Certification and Transparency, Mimeo, Harvard University.

Faure-Grimaud, A., and Gromb, D. (2004) Public Trading and Private Incentives, Review of Financial Studies 17, 985-1014.

Faure-Grimaud, A., Peyrache, E., and Quesada, L. (2009) The ownership of ratings, RAND Journal of Economics 40, 234-257. 
Gondat-Larralde, C., and James, K.R. (2008) IPO Pricing and Share Allocation: The Importance of Being Ignorant, Journal of Finance 63, 449-478.

Grinblatt, M., and Hwang, C.-Y. (1989) Signaling and the pricing of new issues, Journal of Finance 44, 393-420.

Hansen, R. (2001) Do investment banks compete in IPOs? The advent of the $7 \%$ plus contract, Journal of Financial Economics 59, 313-46.

Jullien, B., and Mariotti, T. (2006) Auction and the Informed Seller Problem, Games and Economic Behavior 56, 225-258.

Kutsuna, K., and Smith, R. (2004) Why Does Book Building Drive Out Auction Methods of IPO Issuance? Evidence from Japan, Review of Financial Studies 17, 1129-1166.

Laffont, J.-J., and Martimort, D. (2000) Mechanism Design with Collusion Proof and Correlation, Econometrica 68, 309-342.

Leland, H., and Pyle, D. (1977) Information Asymmetries, Financial Structure and Financial Intermediaries, Journal of Finance 32, 371-387.

Leite, T. (2006) Bookbuilding with Heterogeneous Investors, Journal of Financial Intermediation 15, 235-253.

Li, X., and Masulis, R.W. (2004) Venture Capital Investments by IPO Underwriters: Certification, Alignment of Interest or Moral Hazard? Mimeo.

Li, X., and Masulis, R.W. (2007) How do venture investments by different classes of financial institutions affect the equity underwriting process? Mimeo.

Loughran, T., and Ritter, J. (2004) Why Has IPO Underpricing Changed Over Time? Financial Management 33, 5-37.

Mathis, J., McAndrews, J., and Rochet, J.-C. (2009) Rating the raters: Are reputation concerns powerful enough to discipline rating agencies? Journal of Monetary Economics $\mathbf{5 6}, 657-674$.

Megginson, W.L., and Weiss, K.A. (1991) Venture Capitalist Certification in Initial Public Offerings, Journal of Finance 46, 879-903.

Michaely, R., and Shaw, W.H. (1994) The Pricing of Initial Public Offering: Tests of Adverse-Selection and Signaling Theories, Review of Financial Studies 7, 279-319.

Muscarella, C.J., and Vetsuypens, M. R. (1989) A simple test of Baron's model of IPO underpricing, Journal of Financial Economics 24, 125-135.

Myers, S.C., and Majluf, N.S. (1984) Corporate Financing and Investment Decisions When Firms Have Information that Investors Do Not Have, Journal of Financial Economics 13, 187-221.

Nimalendran, M., Ritter, J., and Zhang, D. (2007) Do Today's Trades Affect Tomorrow's IPO Allocation? Journal of Financial Economics 84, 87-109.

Pagano, M., Panetta, F. and Zingales, L. (1998) Why do companies go public? Journal of Finance 53, 27-64.

Puri, M. (1999) Commercial banks as underwriters: implications for the going public process, Journal of Financial Economics 54, 133-163.

Reuter, J. (2006) Are IPO Allocations for Sale? Evidencefrom Mutual Funds, Journal of Finance 61, 2289-2324.

Ritter, J.R., and Welch, I. (2002) A Review of IPO Activity, Pricing, and Allocations, Journal of Finance 57, 1795-1828.

Sherman, A. E. (1999) Underwriter Certification and the Effect of Shelf Registration on Due Diligence, Financial Management 28, 5-19.

Sherman, A. E. (2005) Global trends in IPO methods: Book building versus auctions with endogenous entry, Journal of Financial Economics 78, 615-649. 
Skreta, V., and Veldkamp, L. (2009) Ratings shopping and asset complexity: A theory of ratings inflation? Journal of Monetary Economics 56, 678-695.

Welch, I. (1989) Seasoned Offerings, Imitation Costs, and the Underpricing of Initial Public Offerings, Journal of Finance 44, 421-449.

Zingales, L. (1995) Insider Ownership and the Decision to Go Public, Review of Economic Studies 62, 425-448. 